\title{
LA PEDAGOGÍA ÉTICA EN LOS CUENTOS PINTADOS, FÁBULAS Y VERDADES DE RAFAEL POMBO DESDE LA PERSPECTIVA METODOLÓGICA DE WALTER BENJAMIN
}

\section{Marisol Moncada Vivas \\ 2116781}

Universidad Santo Tomás

División de Filosofía y Teología

Facultad de Filosofía y Letras

Maestría en Filosofía Latinoamericana

Bogotá D.C. Colombia 2016 


\title{
LA PEDAGOGÍA ÉTICA EN LOS CUENTOS PINTADOS, FÁBULAS Y VERDADES DE RAFAEL POMBO DESDE LA PERSPECTIVA METODOLÓGICA DE WALTER BENJAMIN
}

\author{
Marisol Moncada Vivas \\ 2116781
}

Trabajo de investigación presentada como requisito parcial para optar al título de:

Licenciado en Filosofía y Lengua Castellana

Director:

Ángel María Sopó Ph. .D.

\begin{abstract}
Línea de investigación:
Estudios sobre historia del pensamiento y la cultura en Colombia y América Latina. Grupo de Investigación:

Fray Bartolomé de las Casas, O.P.
\end{abstract}

Universidad Santo Tomás

División de Filosofía y Teología

Facultad de Filosofía y Letras

Maestría en Filosofía Latinoamericana

Bogotá D.C. Colombia

2016 


\title{
LA PEDAGOGÍA ÉTICA EN LOS CUENTOS PINTADOS, FÁBULAS Y VERDADES DE RAFAEL POMBO DESDE LA PERSPECTIVA METODOLÓGICA DE WALTER BENJAMIN
}

\begin{abstract}
«Cuando el impulso de jugar repentinamente invade a un adulto, esto no significa recaída en la infancia. Por supuesto jugar siempre supone una liberación. Al jugar los niños, rodeados de un mundo de gigantes, crean uno pequeño que es el adecuado para ellos; en cambio el adulto, rodeado por la amenaza de lo real, le quita horror al mundo haciendo de él una copia reducida.»
\end{abstract}

Walter Benjamin ${ }^{1}$

«El niño es una bomba aspirante, no de razonamientos que lo fatigan, sino de imágenes; es esencialmente curioso, práctico y material; quiere que se le enseñe objetivamente, lo mismo que a los salvajes y a toda naturaleza primitiva.»

Rafael Pombo ${ }^{2}$

\section{Planteamiento y Formulación del Problema}

Los escritos de Walter Benjamin reflejan una persona que no negó su origen, sino que siempre se definió a sí mismo como "un hombre de la burguesía acomodada"3. Esto le permitió tomar la decisión de mostrarse como coleccionista e historiador. Además, sus ideas sobre filosofía, crítica, política, estética, educación y literatura hacen de él, un escritor.

Rafael Pombo, el poeta de los niños en nuestro medio, fue un hombre que dedicó su vida a escribir sonetos, historias y cuentos alusivos a la formación integral de los niños y los jóvenes, producto de la influencia que recibió de poetas y escritores norteamericanos como Otto Speckter, George Moir Bussey, Robert Dodsley durante su estadía en Nueva York. Sus cuentos se fundan en fabulistas como Esopo, La Fontaine, Iriarte y Lessing.

Por esta razón, Los cuentos pintados, Fábulas y Verdades de Rafael Pombo son el objeto principal en esta investigación, ya que a través de ellos se ve la posibilidad de relacionarlo con Benjamin, quien tuvo interés por la poesía que le llegó a través de Christoph Friedrich Heinle ${ }^{4}$ quien era un poeta productivo que se reservaba el papel de hombre de letras y que se proponía descifrar lo espiritual en sus distintas manifestaciones. Su repentina muerte hace que Benjamin empiece a componer sonetos dedicados a la amistad y a la memoria de su

${ }^{1}$ BENJAMIN. Walter, Juguetes antiguos, en Escritos. La literatura infantil, los niños y los jóvenes, Buenos Aires: Ediciones Nueva Visión, 1989, 83. En: www.mercaba.org/.../Benjamin/La\%20literatura\%20in última consulta: 09 de diciembre de 2015. Cfr. BENJAMIN. Walter, Obras, Libro IV, vol. 2, Madrid: Editorial Abada, $2010,470$.

${ }^{2}$ POMBO. Rafael, Fábulas y Verdades, Bogotá: Círculo de Lectores, 1984, 280.

${ }^{3}$ WITTE. Bernd, Walter Benjamin. Una biografía, Barcelona: Gedisa, 2002, 9.

${ }^{4}$ Poeta y filólogo alemán 
amigo. La gran influencia de su amiga Adrienne Monnier 5 , le permite tener una mayor cercanía a la poesía, la cual habitó en él hasta el fin de sus días.

Pombo y Benjamin son dos autores que no son contemporáneos, pero que a través de su pasión por las letras reflejan su preocupación por la formación ética de las nuevas generaciones y, a su vez, son ellas las que hicieron que su pensamiento y experiencias sean conocidas hoy en día.

De lo anterior, surgió la pregunta: ¿Cuál es la pedagogía ética en Los Cuentos Pintados, Fábulas y Verdades de Rafael Pombo desde la perspectiva metodológica de Walter Benjamin?

Para comentar este interrogante, debo mostrar que Benjamin fue, ante todo, un escritor que se interesó por la literatura, en especial, por la literatura infantil, por coleccionarla y reflexionar sobre ella para conocer el juego, el recuerdo, la experiencia mimética y derivar métodos para la formación ética y el trato pedagógico del niño y del joven. De igual modo, Pombo con su poesía, fábulas e ideas filosóficas para la formación de valores éticos, estéticos y ciudadanos en el niño, defendió y promovió el verso como instrumento pedagógico para la educación infantil y juvenil, ya que él confiaba firmemente que es el medio que permite organizar una sociedad y lograr una convivencia pacífica, guiada por el respeto, la honestidad y las buenas costumbres.

\section{Objetivos}

\section{Objetivo General}

- Comprender la pedagogía ética en Los Cuentos Pintados, Fábulas y Verdades de Rafael Pombo desde la perspectiva metodológica de Walter Benjamin.

\section{Objetivos Específicos}

- Relacionar Los Cuentos Pintados, Fábulas y Verdades de Rafael Pombo con la teoría de Walter Benjamin sobre la literatura infantil.

- Describir la pedagogía ética de Rafael Pombo desde el punto de vista metodológico de Walter Benjamin

- Reconocer el nexo existente entre la pedagogía ética en el planteamiento de Rafael Pombo y la teoría del juego de Walter Benjamin.

\footnotetext{
${ }^{5}$ Poeta, editora y librera francesa, fue muy conocida en el ambiente literario del París modernista, entre las décadas del 20 y los 30 del siglo XX.
} 


\section{Justificación}

Este proyecto analiza la pedagogía ética en Los Cuentos Pintados, Fábulas y Verdades de Rafael Pombo desde la perspectiva metodológica de Walter Benjamin. Estos cuentos, fábulas y relatos muestran un lenguaje de fácil comprensión y una creación de personajes literarios cercanos a los niños, como El renacuajo paseador, La pobre viejecita, Michín, El gato bandido, impulsando su creatividad a través de enseñanzas, que se manifiestan en el juego, la musicalidad, la rima, los contenidos y valores, herramientas didácticas que permiten aprender, pensar, crear, transformar y ver el mundo de distintas maneras a diferencia del adulto.

El niño desarrolla con el cultivo de una memoria extraordinaria; y es grande error el común decir que sólo le agradan cosas pueriles y sin interés para personas mayores. El citado señor Marroquín (veterano observador e institutor) años atrás ha advertido que, al contrario, no se divierten en cuentos tontos y en lenguaje de nodriza, sino en invenciones, relatos, novelas, comedias, etc., de verdadero interés para todos. Complacénse además mucho en que se les trate como a grandes por la ambición de serlo, y por la vanidad que empieza apuntar en ellos... (Pombo, 1984, pág. 159).

Rafael Pombo expresa su concepción de la infancia mostrando que el niño es cercano al ritmo y a la musicalidad del lenguaje, por eso utiliza el verso como forma de atracción y placer, porque es consciente de que la atención del infante se pierde fácilmente, y su método está concebido, según la exigencia del niño, quien necesita brevedad y variedad. Pombo no teme que el niño se enfrente a cosas complicadas, puesto que valora su capacidad de imaginación y, más aún, está seguro de la nobleza, de la dificultad y de los frutos posteriores de la memoria afirmando que son «las piezas del curso nuevo de lectura serán extensas, y muchas serias. Aunque de niño no entiendan las últimas, ése es el tiempo de aprenderlas de memoria, para cuando puedan entenderlas» (Pombo, 1984, pág.343).

Sus cuentos rompen la frontera entre la realidad y la ficción, para construir un camino fantástico que consolide las vivencias del niño y así transformar en enseñanzas las experiencias de la vida. Pombo contó con la cualidad de tener un oído musical y de poseer una rica imaginación, esto bastó para que creara cuentos rimados, con personajes simpáticos, traviesos, crueles, tontos, ridículos; en fin, un conjunto diverso, en donde los animales y los personajes humanos encarnan las cualidades y defectos de los niños y de los adultos.

Por otra parte, en Infancia en Berlín hacia 1900 y en Reflexiones sobre niños, juguetes, libros infantiles, jóvenes y educación brindan una metodología donde la experiencia, el juego, el recuerdo, la mimesis y la infancia son elementos esenciales para que los niños y jóvenes ejerzan la libertad, la cual como signo de autodesarrollo, les permite obtener el poder creador y la concepción de lo nuevo, posibilitando la modificación de los valores implantados por los adultos.

El método que brinda Benjamin parte de la teoría del juego fundada por Huizinga y de la propia experiencia con su hijo Stefan en donde se le ha dado prioridad a jugar hacer otro, a la actitud lúdica frente al mundo, a jugar con lo diferente y hacerlo semejante y a la imaginación. 
El juego infantil se halla completamente saturado de conductas miméticas, y su campo no se encuentra en modo alguno a lo que el hombre puede imitar en otro. El niño no sólo juega a «hacer» el comerciante o el maestro, sino también el molino de viento y la locomotora. (Benjamin, 1987, pág. 167).

El juego no opera saliéndose de la experiencia en un ejercicio de abstracción, sino que desde la experiencia se toma registro del modo en que lo lúdico se muestra; de tal suerte que entre mayor sea el número de lugares desde los cuales tales puntos de semejanza, repetición, vaivén, interactúen a través de un carácter libre y lúdico, logran una mayor riqueza de experiencia.

Para Benjamin, el libro infantil resalta el quehacer del niño «es una pequeña enciclopedia de su vida donde encuentran su lugar los lápices de color y el correo infantil, juegos de carreras y colecciones de flores para colorear, sobres para cartas, "gimnasia de letras" y columnas de palabras» (Benjamin, 1986, pág. 126) puesto que, el niño no se conforma con una única forma de aprender, sino que a partir de su experiencia, crea modos de aprendizaje como el coleccionar imágenes, estampillas, juguetes, muñecas, maneras de creatividad que hacen que el niño y el joven cambie su mundo a su gusto y puedan ser ellos mismos.

Esta teoría del juego de Huizinga y de Benjamin se ha complementado con la lectura sobre las Cartas sobre la educación estética del hombre de Schiller y el capítulo sobre «El juego como hilo conductor de la explicación ontológica» de Verdad y Método I; de Gadamer.

La indagación de esta problemática se realiza para entablar la relación entre la literatura de Rafael Pombo y la metodología de investigación de Walter Benjamin. Además, tiene la intención de mostrar que Pombo no solo es un poeta romántico, sino un pedagogo que impulsó las costumbres y la formación moral en niños y jóvenes. Benjamin, igual que Pombo, se caracteriza por considerar las relaciones entre juego, literatura infantil y pedagogía con el objetivo de darle un giro distinto a la pedagogía donde infantes y jóvenes hacen de su imaginación un camino de libertad y de trasformación frente a su vida y su mundo.

Esta investigación aporta al proyecto del Semillero «Fenomenología y Hermenéutica. Daniel Herrera Restrepo» sobre la recepción filosófica de Walter Benjamin en Colombia (1962-2013) y es una oportunidad para conocer y aplicar la metodología de Benjamin a la literatura infantil de Rafael Pombo y constituye un acercamiento a la investigación de la pedagogía ética en Colombia y América Latina.

En el ámbito profesional, mi interés es investigar la teoría sobre la literatura infantil y su implicación pedagógica en Walter Benjamin, debido a que su trabajo filosófico está basado en influencias pedagógicas que adquirió de Gustav Wyneken ${ }^{6}$, de construir en los jóvenes el interés crítico frente a la sociedad en que viven y el compromiso de transformarla, a través de una educación que les permitiera adquirir conciencia de su propio destino como renovación del espíritu humano.

\footnotetext{
${ }^{6}$ Fue una de las personalidades más sugestivas y complejas de ese vasto movimiento de renovación pedagógica que se registró en Estados Unidos y Europa a partir de finales del siglo XIX, conocido como "la nueva educación". Creador de las comunidades escolares libres, donde la juventud va a educarse no "para el servicio del Estado ni de otra agrupación particular sino sólo al de la verdad.
} 
Benjamin considera que los jóvenes deben ejercer la libertad como un signo de autodesarrollo, que les permite obtener el poder creador y de concepción de lo nuevo, lo cual posibilita la trasformación de los valores implantados por los mayores.

De ahí partió la idea de relacionarlo con la literatura infantil de Rafael Pombo, ya que este poeta-pedagogo está convencido que el niño y el joven se les puede educar con agrado mediante la poesía, la cual posee la esencia del juego que se manifiesta en la capacidad de trasformar un objeto en otro. Lo anterior, hace que la metodología de ambos autores constituya una pedagogía ética que construya el tejido social y la convivencia moral de la sociedad.

\section{Estado de la cuestión}

El siguiente estado de la cuestión plantea una selección de autores que han investigado el pensamiento de Benjamin y de Pombo aportando interpretaciones respecto a la metodología del filósofo alemán y los aportes educativos que brindan los cuentos infantiles del poeta colombiano.

Estos artículos son tomados de bases de datos, especialmente en EBSCO y revistas electrónicas como SCIELO y DIALNET. De los cuales, destaco quince artículos en lengua castellana y portuguesa. Hasta el momento la búsqueda no arroja artículos o comentarios sobre el tema en inglés o en francés. De los quince artículos encontrados, tres están en portugués y presentan un carácter propedéutico sobre la relevancia del juego y la literatura infantil en el pensamiento de Benjamin.

Especifico los siguientes: el ensayo de Maritza Maciel Castrillón Maldonado ${ }^{7}$ As margens da alegria. $O$ invisivel na formação do ser humano moderno, (Las márgenes de la alegría. Lo invisible de la formación del hombre moderno) que busca conciliar literatura e historia de la Pedagogía en el sentido de problematizar los valores del proyecto Iluminista de formación. Igualmente, discute los principios de los pensamientos sociales, políticos y educativos establecidos en Europa Occidental partiendo del momento histórico donde la idea de la racionalidad científica se instituye como centro del proyecto citado.

Para ello, analiza el cuento de Guimarães Rosa Los bordes de la alegría, mediante las alegorías producidas por Benjamin, teniendo como fin mostrar la constitución de los valores del campo educativo que contribuyen a la formación de los niños. Para indicarlo se considera la formación del ser humano requerido por el proyecto moderno, colocándolo en la experiencia vivida.

En relación con lo anterior, Tatielle Rita Souza da Silva ${ }^{8}$ en Literatura, educação e alteridade - a escritura como experiência de formação (Literatura, educación y alteridad. La

\footnotetext{
${ }^{7}$ Se graduó en Pedagogía por la Universidad de Mato Grosso (1993), Maestría en Educación de la Universidad Federal de Río Grande del Sur (2001); doctorado en Educación de la Universidad Federal Fluminense (2009), tiene experiencia en el área de Educación, que actúa sobre los siguientes temas: la educación de la primera infancia, programas de estudios, la vida cotidiana, la literatura infantil, la subjetividad, de imagen, de rutina y de ritmo.

${ }^{8}$ Graduado en Educación de la Universidad Federal de Río Grande do Sul, terminado en 2006. Doctorado en Educación de la Universidad Federal de Río Grande do Sul, en la línea de la ética de la investigación, la alteridad y
} 
escritura como experiencia de formación) tiene como objetivo mostrar la relación entre literatura y educación mediante la experiencia de formación, la cual permite pensar la potencialidad de la experiencia estética de la literatura y el discurso pedagógico. Esto hace que el estudio parta de la relación entre literatura y pedagogía que conduce a nuevos planteamientos y de la narrativa y de los discursos pedagógicos. Igualmente, la autora tiene como teóricos a Walter Benjamin, Giorgio Agambem, Clarice Lispector y Roland Barthes abordando temas como lenguaje, infancia y alteridad para pensar la elaboración simbólica de la experiencia existencial a través de la literatura.

La hipótesis que desarrolla es que la presencia de la literatura en el escenario escolar produce un desplazamiento del lugar y de la función docente, inscribiendo modificaciones importantes, que alteran los contornos que forman la postura pedagógica investida de un saber-poder.

Siguiendo el ámbito pedagógico Lluís Ballester Brage ${ }^{9}$ y Antonio Juan Colom Cañellas ${ }^{10}$ en su texto Juventud y pedagogía (sobre la génesis del pensamiento de Walter Benjamin) resaltan la falta de atención de los primeros escritos de Benjamin, los cuales aluden a cuestiones pedagógicas que son consideradas como pensamientos secundarios en comparación a sus aportes socio filosóficos, lo que hace que los pedagogos dejen a un lado al autor y opten por no considerarlo. La pedagogía para Benjamin se constata en la libertad, la cual no es un programa sino una voluntad de realización que debe florecer en los jóvenes a través de la escuela.

Además, esta idea de libertad debe tener como base la ética para que la juventud se encuentre con su verdadero espíritu y ser fiel al mismo dando origen a una cultura autentica de la juventud. Brage y Cañellas indican que la posición que defendía Benjamin es la de considerar «la escuela debe transmitir como valor educativo no tanto el «arte por el arte», que sólo tiene sentido para el artista, sino la esencia del valor estético para despertar el espíritu del alumno» (2011, pág. 93-94). Por consiguiente, el interés de estos autores es demostrar que la pedagogía no formó parte importante en la obra del pensador alemán, pero consideran que en la idea de libertad está la verdadera pedagogía.

José María Pérez- Agote Aguirre ${ }^{11}$ está de acuerdo con lo anterior con su artículo Las inquietudes pedagógicas del joven Benjamin: el poder redentor de la juventud y la educación

\footnotetext{
Lenguaje en la Educación. Maestría en Educación de la Universidad Federal de Río Grande do Sul Tiene experiencia en las escuelas municipales y estatales, sobre todo en los primeros años de la educación primaria y la juventud y el modo de la educación de adultos.

${ }^{9}$ Doctor en Sociología y en Filosofía, Diplomado en Trabajo Social. Ha trabajado como educador y trabajador social en el Ayuntamiento de Palma, Cáritas y en el Consell de Mallorca. Desde 1997 es profesor de Métodos de Investigación en la Facultad de Educación de la UIB.Líneas de investigación: Competencia i Prevención Familiar Sociología de la juventud -Necesidades - Prostitución - Métodos de investigación.

${ }^{10}$ Profesor de la Universidad de las Islas Baleares, Departamento de Ciencias de Educación, en el área de teoría e historia de la educación. Sus últimas obras son Desarrollo sostenible y educación para el desarrollo (Octaedro, 2000), Pedagogía institucional (Síntesis, 2000) y Teoría de la educación (Síntesis, 2001).

${ }^{11}$ Licenciado en Ciencias Políticas y Sociología por la Universidad de Deusto y doctor en la misma disciplina por la Universidad del País Vasco. Actualmente es profesor doctor en el Departamento de Sociología de la Universidad Pública de Navarra. Trabaja principalmente en procesos de cambio en las sociedades modernas desde ámbitos como la teoría sociológica y la sociología de la educación.
} 
brindando un análisis sobre los primeros escritos de Benjamin, los cuales son dedicados en buena parte a la juventud y a la educación reflejando un interés crítico por el tiempo presente y el compromiso por transformarlo. El autor resalta la idea de una juventud como movimiento cultural que pone a su alcance el presente y el futuro, ya que el optimismo pedagógico ilustrado es el punto fundamental del análisis de la modernidad.

El autor afirma que Benjamin estaba totalmente sometido al influjo pedagógico de Gustav Wyneken, pero al romperse esta unión, el interés de Benjamin por la educación de la juventud se desborona considerablemente. No obstante, en la década de los veinte retorna a su tendencia educativa para elaborar una crítica a la pedagogía burguesa de su infancia partiendo desde una perspectiva revolucionaria que encontró en el teatro, los libros y juegos infantiles; aquellos que despiertan la fuerza interna del futuro en los niños.

Pérez- Agote culmina resaltando que la meta de la educación ya no puede ser entendida como una simple reproducción y renovación lineal y progresiva de los valores que redime el presente a través de la orientación de un futuro, sino que la irrupción de lo nuevo desarrolla lo mesiánico, lo cual redime el pasado partiendo del presente de una forma que el poder redentor de la juventud y la educación libere el pasado de las cadenas que oprimen, pero que a la vez reintegra la esperanza a un mejor futuro.

Por otro lado, Alejandro Fielbaum $\mathrm{S}^{12}$ en su ensayo La filosofía de la infancia de Walter Benjamin destaca lo pequeño como aquello que tiene gran relación con la idea de infancia, ya que en esta reside el particular interés benjaminiano, debido a que la infancia muestra al adulto, la ternura de su pasado como la necesidad de su futuro. Fielbaum enfatiza que Benjamin cree que el niño carece de toda noción de culpa moral, lo que cuestiona el interés ilustrado en una educación moralizante, la cual no sólo traspasaría al niño una responsabilidad por la que debe hacerse responsable, sino también una cierta subjetivación que le resulta igualmente ajena.

El aprendizaje del niño no será experimentado desde cierta individualidad en donde se separa los restantes sujetos y objetos, sino que en la comunidad podría adquirir un nuevo saber, permitiéndole al niño a que experimente la sociabilidad como un ámbito que no separa su ubicación en el mundo, pues, la relación y el aprendizaje se enmarcan directamente en la singular temporalidad de la infancia, cuyas formas de significación no podría sino estar mediadas por cierta dimensión lúdica, «Comer, dormir, vestirse, lavarse, tienen que inculcarse al pequeño en forma de juego, con versitos que marcan el ritmo» (Fielbaum, 2012, pág. 73).

El autor considera que para Benjamin, la indeterminable creatividad del niño nacerá por la particular relación que traza con los objetos, los cuales, sin importar el tipo o calidad del objeto, le brindará una inusitada atención, otorgándole un uso sin valor alguno. Dado que, la posibilidad de iniciativa del niño, hallará su límite ante tan inocente imaginación haciendo que el mundo del niño goce de cierta autonomía ante los tristes regímenes de sentido que el adulto buscará imprimirle. De ahí, la importancia que el autor ve en Benjamin frente al juguete, el cual poco se relaciona con la realidad minimizada, pero la experiencia del niño organizará

\footnotetext{
${ }^{12}$ Sociólogo y licenciado en Filosofía, Pontificia Universidad Católica de Chile. Estudiante de Magíster en Estudios Latinoamericanos, Universidad de Chile.
} 
creativamente la percepción desde tal inventiva, ya que la permanencia de la materialidad del juguete no impide la diferencia del juego.

Es así que la figura del niño para Fielbaum le permite a Benjamin, imaginar una experiencia distinta de la humanidad sin sujeto ni propiedad, sino que situada en formas de compartir y recrear que, al alterarse infinitamente, no sólo resignifican al mundo sino también allí se inserta a través de las singulares dinámicas del juego.

Del mismo modo, Tyson Lewis ${ }^{13}$ en su artículo A Constellation Of Childhood (Una constelación de la Infancia) considera que en La obra de los pasajes de Benjamin se explora las actividades simples de la infancia para encontrar instancias paradigmáticas del pensamiento dialéctico y de la teoría estética del autor alemán. Las reflexiones sobre la infancia que hace Benjamin revelan los momentos ingenuos e intuitivos de las complejas operaciones conceptuales que son, después, perdidas en los adultos que quedan capturados en un mundo unidimensional de producción y consumo. Según Lewis, el recuerdo es la principal metodología para el pensamiento filosófico, ya que el niño reúne la filosofía y la experiencia. Además, alude a una fenomenología de la infancia que se basa en los detalles del juego infantil, los cuales son inconsecuentes y mínimos en Benjamin, pero el autor los integra en una nueva constelación de significados a través del proceso autobiográfico reflexivo.

El artículo de Silvana Vignale ${ }^{14}$, Infancia y experiencia en Walter Benjamin: jugar a ser Otro, coincide con lo anterior, ya que para ella, el concepto de infancia, permite esbozar una subjetividad, que se constituye desde la experiencia. Vignale considera que la facultad mimética se convierte en la experiencia de "jugar a ser otro, dando la posibilidad de ir siendo, cada vez, un sí mismo a partir de lo otro, permitiendo al niño que conozca a partir de su propia experiencia del juego y no de un discurso verdadero sobre el mismo.

Por esta razón, la autora considera que la capacidad de producir semejanzas se manifiesta en el niño a través de imágenes y asocia el juego a lo que Benjamin llamaba «la ley de la repetición», porque nada hace más feliz al niño que el "otra vez", porque para ella, «el juego es una de las experiencias primigenias, el lenguaje, si bien es el grado cúlmine de la facultad mimética, es original en el hombre. El lenguaje nos constituye» (Vignale, 2009, pág. 90). De modo que, la infancia, el lenguaje y el juego permiten que la pedagogía parta no solo de relaciones de saber sino también de la experiencia.

Alberto Verón ${ }^{15}$ en su ensayo Juguetes e Infancia en Walter Benjamin, analiza los aspectos más relevantes de los escritos de este autor y lo hace de una manera filosófica y literaria, basándose en la infancia, la cual es la práctica del juego colectivo, es el ejercicio

\footnotetext{
${ }^{13}$ Se graduó con un doctorado en la filosofía educativa de la UCLA en 2006. Antes de unirse al departamento de historia del arte y la educación artística en UNT, fue profesor de fundaciones cursos educativos en la política, la filosofía y la sociología de la educación en la Universidad Estatal de Montclair, Nueva Jersey. Su beca se centra en las intersecciones entre una fenomenología de la percepción, la biopolitica (como las políticas del cuerpo), y el arte de educación / apreciación estética

${ }^{14}$ Profesora de Grado Universitario en Filosofía, por la Facultad de Filosofía y Letras de la Universidad Nacional de Cuyo, Mendoza, Argentina. Becaria de CONICET. Doctoranda de la Universidad Nacional de Lanús.

${ }^{15}$ Diplomado en filosofía y letras, U de Caldas; Maestría en comunicación, UTP, comentarista y critico cultural de la región; profesor y director del área de humanidades U católica popular de Rda. Y profesor U. libre de Pereira
} 
permanente de la observación y es la recreación del mundo a partir de los detalles más insignificantes. Que al reconocer al niño en su energía expresiva, la pedagogía se liberó de la vieja idea de que el niño era un ser mejor, en cuanto interiorizara más rápidamente los comportamientos adultos.

Según Verón, Benjamin elaboró una crítica pedagógica, una interpretación del juego y un análisis de la literatura infantil que le conectan a un propósito mayor, el de «una reconstrucción teórica de la modernidad que al mismo tiempo diera cabida al ideal de reconciliación entre el ser humano y el mundo»(Benjamin, 1996, pág.7). Esto hace que la afirmación de la niñez sea universo autónomo, dotado de características propias y sobre todo capaces de crear y de observar el mundo de los adultos.

Mariela Peller ${ }^{16}$ con su artículo Un recuerdo de infancia, juego, experiencia y memoria en los escritos de Walter Benjamin, parte de la niñez, la memoria y la experiencia, analizando las diversas figuras y prácticas que para Benjamin, encarnan la posibilidad de obtener experiencia en un mundo donde actualmente se está extinguiendo. Peller utiliza las figuras que Benjamin alude en sus textos como: El narrador, el copista, el coleccionista, el poeta y el infante, para acercarse a un nuevo renacer de la experiencia.

Sin embargo, Tamara Grigorowitschs ${ }^{17}$ en su escrito: Juego, mimesis e infancia: el papel de jugar en los procesos de construcción del self, aborda con una mirada sociológica el papel del juego en los procesos de socialización infantil y de la formación del self en la infancia. Así mismo, recurre a autores clásicos como Benjamin y Georg Herbert Mead y de algunos de sus intérpretes contemporáneos, como Gunter Gebauer y Christoph Wulf, que organizaron esta discusión en torno del concepto de mimesis.

También, el artículo presenta un análisis de dos imágenes la de El Mummerehlen y El Jorobado presentes en La infancia en Berlín alrededor de 1900, de Benjamin, que plasma de forma autobiográfica el papel del juego para la formación del self en la infancia. La primera imagen según la autora es un camino que conecta la construcción del self (la propia imagen) y los procesos de socialización (el mundo social, a la realidad) y la segunda simboliza el vacío del yo, autodistanciamento de las relaciones que se producen mimética a través del juego en la infancia; que representa la posibilidad de ser sujeto y, por lo tanto, el desarrollo del self.

En la búsqueda se encontró una tesis de maestría La escritura literario-filosófica de Walter Benjamin: El Filósofo como autor presentada por Luis de la Peña Martínez, su interés se centra en examinar los 73 sonetos escritos en memoria de su amigo Fritz Heinle y el libro de Dirección Única en el que según él, Benjamin aplica la técnica del montaje literario a un conjunto de aforismos y reflexiona sobre el oficio del escritor.

\footnotetext{
${ }^{16}$ Docente en la Universidad de Buenos Aires (Argentina). Está finalizando su tesis de maestría en sociología de la cultura y análisis cultural en el Instituto de Altos Estudios Sociales de la Universidad de San Martín. Becaria doctoral del Consejo Nacional de investigaciones científicas y Técnicas y candidata al doctorado en ciencias sociales de la UBA. Investigadora del Instituto Interdisciplinario de Estudios de Género (IIEGE) de la Facultad de Filosofía de Letras.

${ }^{17}$ Es licenciada en Ciencias Sociales (2001), Maestría en Sociología de la Educación (2007) y Doctora en Sociología (2012), todos ellos realizados en la Universidad de São Paulo
} 
El objetivo de Martínez es vincular la producción literaria de Benjamin a través de sus ideas sobre el lenguaje, y de esta forma demostrar la forma como el autor alemán plantea una concepción acerca de la escritura y la literatura como su médium ${ }^{18}$ de su pensamiento. Su hipótesis parte en que para Benjamin la escritura no era un simple medio de comunicación de ideas, sino un médium en que su filosofía tomaba forma, un contorno donde el lenguaje se expresa así mismo.

Para referirme a la temática de los cuentos infantiles de Rafael Pombo, resalto dos tesis, la primera La literatura Infantil de Rafael Pombo, un camino hacia la vivencia de los valores humanos de Nelly González Gamboa, Magalys de la luz Palacio Amaya y Gloria Patricia Rojas Cetina, quienes establecen que en la corriente de la tradición literaria se destaca como antecedente a Rafael Pombo quien fue considerado durante varios años como el poeta nacional por excelencia y también como el padre poético de los niños colombianos.

Pombo según las autoras es quien inaugura la literatura infantil en Colombia gracias a su calidad estética y literaria de sus cuentos y fábulas. El proyecto tiene varios objetivos, como el de rescatar la importancia de las obras de Rafael Pombo, mediante un reconocimiento histórico, el de redescubrir las posibilidades axiológicas presentes en las obras del autor, representadas en los personajes y el de entablar una relación básica entre la literatura y la pedagogía con el fin de enriquecer el quehacer educativo.

De igual forma, la tesis Natalia Andrea Álzate Literatura Infantil y Literatura Fantástica: El surgimiento de la Infancia es una articulación historia-literatura-infancia para tener un acercamiento a la literatura de Rafael Pombo y encontrar allí elementos de orden simbólico, a través de los cuales se pueda comprender la concepción de niñez y la dimensión estética que rodea a la infancia en las propuestas escriturales del autor. La autora pretende contextualizar la vida y obra del autor, para conocer, a través de sus escritos la configuración estética y literaria que logra cuando dirige sus textos a los niños como público lector.

Alude que en la obra de Rafael Pombo se tuvo un interés por promover principios morales y religiosos, que en algunos casos se presentaba de manera alegórica y se proponían como ideas para educar las mentes más jóvenes. Dichas intenciones derivadas de un romanticismo heredado de Europa, empiezan a contrastarse, a su vez, con la manera particular en que América inició su despertar en éste movimiento cultural y político.

El artículo de Martha Lucía Jiménez Ortiz ${ }^{19}$ y Aurora Gordo Contreras ${ }^{20}$ El cuento infantil: facilitador de pensamiento desde una experiencia pedagógica es un avance de la investigación desarrollada para obtener el título de Magister en Educación, las autoras hacen una indagación desde la experiencia pedagógica utilizando el cuento 'La Pastorcita' de Rafael Pombo, musicalizado por Carlos Vives e ilustrado por Lorenzo Jaramillo. Este ejercicio lo

\footnotetext{
${ }^{18}$ El término "médium", diferente de "medio", es empleado por Benjamin en varios de sus trabajos y constituye una categoría fundamental para la comprensión de sus propuestas filosóficas (cf. Wohlfarth, 1999 y 2009, uno de los estudiosos de la obra de Benjamin que ha marcado con insistencia esta diferencia conceptual y terminológica).

${ }^{19}$ Profesora del Jardín social Comfaboy

${ }^{20}$ Estudiante de la Universidad Pedagógica y Tecnológica de Colombia
} 
desarrollaron con seis niñas de cinco años de edad del Jardín Social Comfaboy del municipio de Toca, Boyacá, con el objetivo de dinamizar el pensamiento a través de aspectos claves en la historia de la infancia, la literatura infantil y analizando su transformación como estrategia de enseñanza en la formación del individuo.

A su vez, el artículo de Beatriz Robledo ${ }^{21}$ Aporte de Rafael Pombo a la literatura Colombiana muestra como este poeta colombiano con su cualidad de genio poético, su conocimiento del lenguaje y de la literatura y su interés por la niñez, lo pusieron en un terreno que le permitió ser visionario, adelantándose a los tiempos y prefigurando una noción literaria para la infancia que se resolvería en el país muchas décadas después.

La autora alude que Los Cuentos pintados y algunos de Los Cuentos morales para niños formales, se han grabado en el recuerdo de generaciones enteras de colombianos: "Rinrín Renacuajo", "Mirringa Mirronga", "La Pobre Viejecita", "Simón el Bobito", "Pastorcita", "El gato bandido", entre otros, ya que en estos cuentos, Pombo logró desarrollar su estética personal relacionada con la literatura infantil, sostenido por la tradición oral inglesa, transforma motivos, imágenes, argumentos, con un estilo propio humorístico, socarrón y no exento de cierta ironía. De igual manera, Robledo considera que él pone a dialogar, conocimiento profundo de ambas lenguas, de su estructura y sus ritmos poéticos y musicales, dos tradiciones: la inglesa y la colombiana.

La autora considera que para que se dé una transformación en la concepción de la niñez, se debe incluir una reforma educativa en la que el niño pueda desarrollar las etapas propias de la niñez: el juego, el aprendizaje a partir de la experiencia, el niño es capaz de divertirse, de crear mundos imaginarios y de interpretar las lecturas. Es ahí que la renovación del concepto de infancia es el mayor aporte de Pombo a las letras infantiles, ya que es quien valoró siempre al niño como lector estético permitiendo el desarrollo cultural de la niñez.

El rastreo de esta literatura específica se resume en los siguientes temas:

1. Literatura infantil y educación. Sobresale el trabajo de Tatielle Rita Souza da Silva porque abre perspectivas de interpretación novedosa

2. El juego y experiencia. Se resalta el artículo de Silvana Vignale porque concibe el juego a la manera de Huizinga, Benjamin y Gadamer, es decir, el juego como repetición.

3. Pedagogía y Filosofía. Sobresale el ensayo de José María Pérez- Agote Aguirre y Alejandro Fielbaum S, debido a que trabajan el asunto desde una mirada fenomenológica e histórica

4. Literatura infantil y ética. Es importante la tesis Natalia Andrea Álzate porque aporta elementos conceptuales para comprensión de la obra de Rafael Pombo desde una axiología

5. Literatura infantil, juego y formación. Se destaca el aporte de Beatriz Robledo y Alberto Verón ambos colombianos por su excelente conocimiento de los autores que se van a trabajar en esta investigación.

\footnotetext{
${ }^{21}$ Magister en Literatura Hispanoamericana por la Universidad Javeriana de Bogotá y es escritora e investigadora en las áreas de literatura infantil y juvenil y en procesos de formación lectora.
} 


\section{REFERENCIAS BIBLIOGRÁFICAS}

Álzate, Natalia. (2012). Literatura Infantil y Literatura Fantástica: El surgimiento de la Infancia: Bogotá, Universidad Nacional de Colombia. http://www.bdigital.unal.edu.co/8367/

Ballester B, Lluís \& Colom C, Antonio J. (2011). Juventud y pedagogía (sobre la génesis del pensamiento de Walter Benjamin). Teoría de la educación, Vol.23, $\mathrm{N}^{\circ}$ 1, pp. 71-106. Recuperado de:http://dialnet.unirioja.es/servlet/articulo?codigo=3787027

Benjamin, Walter. (1987). Dirección Única. Madrid, España: Alfaguara,

Benjamin, Walter. (1989). Escritos. La literatura infantil, los niños y los jóvenes. Buenos Aires, Argentina: Ediciones nueva visión.

Benjamin Walter. (1996) Escritos autobiográficos. Introducción concha Fernández. Madrid, España: Alianza Editorial.

Castrillon, Maritza. (2012). As margens da alegria. O invisível na formaçao do ser humano moderno. Nómadas: revista crítica de ciencias sociales y jurídicas, $\mathrm{N}^{\circ}$. 33, pp. 497-508. Recuperado de http://dialnet.unirioja.es/servlet/articulo?codigo $=3863667$

Fielbaum S, Alejandro. (2012). La filosofía de la infancia de Walter Benjamin. Revista de Filosofía, Vol.71, pp.69-80 ISSN 0798-1171 Recuperado de http://produccioncientificaluz.org/index.php/filosofia/article/view/18247/18235

Gamboa, G, Nelly, Amaya Magalys, Cetina, Gloria (2001). La literatura Infantil de Rafael Pombo, un camino hacia la vivencia de los valores humanos: Chía, Universidad de la Sabana

Grigorovich, Tamara. (2010). Jogo, mimesis e infância: o papel do jogar infantil nos processos de construção do auto.Rev. Bras. Educ. [En línea], vol.15, No.44, pp. 230-246. Recuperado de http://www.scielo.br/scielo.php?script=sci_arttext\&pid=S141324782010000200003\&lang=es

Lewis, Tyson. (2007). A constellation of chilhood. Childhood \& Philosophy, Vol. 3, No. 6, pp. 175-185. Recuperado defile:///C:/Users/PERSONAL/Downloads/DialnetAConstellationOfChilhood-5013872\%20.pdf \}

Martínez, Luis. (2011). La escritura literario-filosófica de Walter Benjamin: El Filósofo como autor: México. Universidad Autónoma de México. https://www.academia.edu/1872965/La_escritura_literariofilos\%C3\%B3fica_de_Walter_Benjamin_el_fil\%C3\%B3sofo_como_autor

Peller, Mariela. (2010) Un recuerdo de infancia, juego, experiencia y memoria en los escritos de Walter Benjamin. Nómadas. Revista Critica de Ciencias Sociales y Jurídica http://pendientedemigracion.ucm.es/info/nomadas/27/marielapeller.pdf

Pérez Agote A, José M. (2009). Las inquietudes pedagógicas del joven Benjamin: el poder redentor de la juventud y la educación. Revista anthropos: Huellas del conocimiento, $\mathrm{N}^{\circ}$ 225, pp. 203-212.

Pombo, Rafael. (1984). Fábulas y Verdades. Bogotá: Círculo de Lectores

Ortiz Jiménez Martha L. y Contreras Gordo Aurora. (2014) El cuento infantil: facilitador de pensamiento desde una experiencia pedagógica. Revista de investigación y pedagogía Praxis Saber. Vol. $5 \mathrm{~N}^{\circ} 10$, pp. 1-20.

Robledo, Beatriz. (2012) Aporte de Rafael Pombo a la literatura Colombiana. Universidad de Antioquia. ISBN0124-0854, $\mathrm{N}^{\circ} 186$, pp. 1-7. 
Souza da Silva, Tatielle R. (2014). Literatura, educação e alteridade - a escritura como experiência de formação. Childhood \& Philosophy, Vol. 10, No. 19, pp. 155-178. Recuperado http://dialnet.unirioja.es/servlet/articulo?codigo $=5013914$

Verón, Alberto. (2002). Juguetes e Infancia en Walter Benjamin. Diálogos Educativos ISSN: 0124-1451, Editorial Papiro. Recuperado de http://revistas.utp.edu.co/index.php/repes/article/view/5283

Vignale, Silvana. (2009). Infancia y experiencia en Walter Benjamin: jugar a ser Otro. Childhood \& Philosophy, $\quad \mathrm{N}^{\circ}$. 9, pp. 77-101. Recuperado de http://dialnet.unirioja.es/servlet/articulo?codigo=3268639

WITTE. Bernd. (2002) Walter Benjamin. Una biografía, Barcelona: Gedis. 